\title{
Comparing the Differences Between Chinese and American Education
}

\author{
Haoyu $\mathrm{Li}^{1, \dagger}$, Jiaxuan $\mathrm{Li}^{2, \dagger}$, Shuming $\mathrm{Xie}^{3, *}{ }^{*}$, Yifei $\mathrm{Zhu}^{4, \dagger}$ \\ ${ }^{1}$ School of Foreign Languages, YanTai University, Tianjin,Tianjin, 264005, China \\ ${ }^{2}$ School of foreign languages, Zhejiang Yuexiu University, Shaoxing, Zhejiang, 312000, China \\ ${ }^{3}$ School of foreign languages, Guangdong Polytechnic College University, Zhaoqing, 510540, Guangdong, China \\ ${ }^{4}$ Shanghai International Studies University Litai Alevel College, Shanghai, Shanghai, China. \\ *Corresponding author. Email: v731@wanfeng.edu.bi. \\ Those authors contributed equally.
}

\begin{abstract}
As we all know, school bullying is aggressive behaviour that takes place on and out of campus and involves students. . It includes both direct bullying and indirect bullying. School bullying is not equal to school violence, which includes school bullying, which is the most common kind of school violence. At present, the phenomenon of school bullying in China and around the USA is very serious. Governments of various countries and international organizations have also issued relevant laws, regulations, policies and documents to deal with school bullying. The concept of comprehensive sexuality education proposed by UNESCO also covers the awareness and response to school bullying. The United States has high-quality education in the world. Although China has made remarkable achievements in educational development in recent years, there are still many problems. There is still a certain gap in education between China and the United States. The formation of this gap is largely due to differences in the structure of schooling governance, cultural reproduction, and gender of the two countries. This article attempts to compare and think about the differences in certain aspects of Chinese and the United States education, find some problems in Chinese education, and propose corresponding countermeasures.
\end{abstract}

Keywords: Schooling of Governance; Education; School Bullying

\section{INTRODUCTION}

The United States has high-quality education in the world. Although China has made remarkable achievements in educational development in recent years, there are still many problems. There is still a gap in education between China and the United States. The formation of this gap is largely due to a series of factors. For example, the factors include the structure of schooling governance, basic education, higher education, and gender differences. In the structure of schooling governance, we cited incidents of corporal punishment and school bullying. This article attempts to compare and think about the differences in certain aspects of Chinese and the United States education, find some problems in Chinese education, and propose corresponding countermeasures. The method we used was to consult the literature and the Internet. The data used in this paper were references to previous papers and journals.

\section{DIFFERENCES IN STRUCTURE OF SCHOOLING GOVERNANCE}

The structure of schooling: there are two parallel school systems in the United States, namely, public and private. Public schools are funded and controlled by three levels of government: federal, state, and local (school districts). The structure of schooling in China: it is mainly based the central structure of schooling governance, supplemented by the joint operation of schools from all walks of life.

Decentralized structure of schooling governance in the United States is concentrated at the grass-roots level-schools and communities, which makes it easier for people to participate. Under this governance, The Unite States students have a high degree of freedom of choice. China has a nationwide education system, which is governed by the central government. Under this governance, although students all over the country can 
get the same and equal education, this has also led to China's selection centered on examinations, which over time stifles the creativity of students. The central structure of schooling governance pays more attention to overall education and ignores the quality of students' education. The following examples analyze and compare the differences in school governance systems between China and the United States.

\subsection{School Bullying}

In recent years, various school bullying incidents have occurred frequently all over the world. The research on school bullying in our country started relatively late, and there are currently no laws and regulations that specifically interfere with school bullying. Therefore, the problem of school bullying has not been well resolved. Among the most serious bullying in schools, there are only protection and preventive measures for minors. In contrast, the United States not only has relevant laws and regulations on school bullying, but also has good governance effects [1].

In China, in the newly revised Law on the Protection of Minors in 2021 [2]. It only clarified the definition of student bullying, and did not elaborate on the punishment of school bullying, and did not specify the punishment for bullies in the occurrence of major vicious incidents. School bullying incidents have been reported frequently and have aroused people's attention. However, because there are no relevant laws and regulations, the judiciary and schools can only adopt a calm attitude and make corresponding adjustments. As far as schools are concerned, improving academic performance is always the highest goal of school education [3]. Therefore, school bullying is not emphasized in China.

The U.S. has an effective intervention system in which the state is the unit, the government, communities, schools, students, parents and other parties cooperate. With legislative support from the federal and state governments, each has formulated quite strict and distinctive anti-bullying regulations based on the local school bullying phenomenon. After the launch of this series of school prevention and control projects, the incidence of school bullying has decreased significantly, and the self-report rate of bullying has also increased, forming a nationwide general attitude against school bullying [4].

Since China's structure of school is central governance, the lack of serious laws and policies on school bullying has led to a lack of practical guidance and excessive exercise of power by school administrators. It is precisely because of the school's inaction, or even inaction, that makes the bullies more rampant. Chinese school administrators have not paid much attention to school bullying. In contrast, in the US, under a disperse governance structure of schooling, school bullying is gradually decreasing, thanks to the flexible structure of schooling.

\subsection{Corporal Punishment}

In China, teachers corporal punishment of students gradually exposed the problem. In September 2021, a junior high school girl was punished by her life teacher to do 150 squats and became disabled [5]. In September 2020, a girl was punished by the teacher for "beating the palm of the hand with a ruler and kneeling" because of the wrong answer to the teacher's question in class, which eventually led to the girl's death [6].

Teachers have the right to discipline students. In these case, we can find that teachers, as school administrators, excessively abuse their power of punishment. China's laws and regulations regarding corporal punishment of teachers are still incomplete, as it is often difficult to define "corporal punishment" and "discipline." But in the U.S., the legislates that the power of corporal punishment is the power of discipline in schools, and it regards corporal punishment that exceeds the legal limit as an illegal act that seriously violates the rights of minors [7]. As early as 140 years ago, the State of New Jersey banned these behaviours by legislation [7].

\section{STYLE PALETTE}

Chinese students receive traditional exam-oriented education in China as well as the characteristic of examoriented education's progress is fast and difficulty is higher. Also have a lot of knowledge points. On the other hand, exam-oriented is more rigid. Many Chinese students can solid their foundation and get high scores by doing a large number of questions. Best primary schools in China select students through exams, so the learning environment and the quality of the teachers are high. However, China's cramming of basic education, students do a lot of exercises such as learning machines. Many students can get high scores by doing a lot of problem sets because they have similar problem sets. Such a boring learning model leads to a lot of primary and secondary school students hate learning.

In this paper, we argue that American education has these disadvantages. Firstly, one of disadvantages is the division of school districts, especially at the high school level. In general, there are two major areas of basic education in America, public and private schools. Students in public schools have to choose the right school according to the place where they live, while for private schools, all the way to high school can largely prevent students from poor schools from working their way up to good schools that further polarize education. Secondly, the lack of elementary teachers in the US. But 
why is American basic education being successful? American basic education emphasizes process from teaching preparation to teaching implementation and evaluation as well as the education of students' thought and behaviours [8]. First of all, preachy learning is ready, and each teacher should write the learning objectives of this lesson on the white board before class. Learning target is from the Angle of students, such as if from the Angle of teachers, it is teaching target. Teachers on the learning objectives of the table is very close, very clear, embodies the students as the centre of teaching and learning thinking. In addition to this, the teacher also needs to write the class steps, so that students have a number of goals and specific teaching in the class.

In addition, all teaching and learning resources are for teaching and learning service, rather than a single display of teaching and learning results. Word Wall has been set up on the walls of many classrooms. On the wall is a list of the core words and phrases learned recently. It is possible that books are not written neatly, and plans are not studied, but in the words of the old teacher, "only the development of thinking to help students", will come out of the classroom can be used for the benefit of each corner.

Finally, American schools attach great importance to the education of students and give students the opportunity to correct their mistakes. Take not wearing school clothes as an example, from the first time not wearing school clothes, to if the dry time not wearing school clothes, there are clear and definite measures, gradually increase the heavy punishment, can be very practical. The development of personality adjustment is the goal and inevitable result of American education. In terms of the school, students run the course system, there is no fixed classroom and class. Secondly, students' selection of courses became multidimensional, with some required courses and many selected courses. Students had the right to choose favourite subjects and teachers. Again, the class to ask students to remember the east and west less, more is the teacher to guide students to ask questions to send a table to see the method, encourage the quality of doubt, so that students develop their own thinking, shaped into a unique personality. In addition, students often have the activity of making choices, which gives them a place to express their will.

American teaching evaluation system and activity design are also conducive to cultivating students' communicative ability. In class activities, it is common for small groups to evaluate each other [9]. For example, teachers and students can evaluate each other. Teachers may select several outstanding or advanced students each week based on their overall development, and students may also select outstanding teachers. In fact, these are all handed over to live with the body. The dynamic design also shows the special point of force cultivation of injection heavy one energy [10]. In addition to cultivating students' survival ability, American education also focuses on cultivating students' social consciousness. American students are required to show evidence of volunteer work and participation in social activities when applying to universities. This shows that cultivating students' social consciousness is one of the goals of American education. Students to participate in the activities of the community, do students volunteers. Students through this kind of a way to contact the society, experience the social character.

The USA has shaped higher education mainly from two aspects. The first aspect is reflected in the hierarchy of American higher education system. Lower-ranking universities focus on developing a popular undergraduate education, top-ranking universities focus on academic research and postgraduate education, and middle-ranking universities focus on practical education and applied research. It can be seen that, on the whole, the American higher education system has indeed organically integrated the three modes. Therefore, American higher education has a reasonable structure and complete function. Another aspect of organic integrations is that research universities can also develop undergraduate education and applied research and practical education of land grant colleges according to needs and market. However, in China, when students enter the universities, their efforts will obviously decline, because the effect of college education on future employment is not obvious, at least students intuitively do not feel how the knowledge can help them gain an advantage in the future employment. But the students who have the goal of studying abroad, guaranteeing postgraduate study and applying for scholarship can often maintain a certain intensity of study, because performance is still one of the quantitative indicators in competition. Many Chinese students just have to study for better grades. Many Chinese college students will do whatever it takes to secure their diplomas by scraping together their dissertations online, bringing cheat sheets to pass exams and asking their classmates register for them when professors call the roll, either copy or scribble their homework.

Overall, American basic education pays more attention to cultivating students' comprehensive quality. Chinese often focuses on students' grades and ignores the rest. Hence, in the US, even some students with poor academic performance may be appreciated by others for their excellent communication skills. But in China, students with poor grades may become introverted because they are looked upon by teachers and classmates with coloured glasses. In the society, they may become the bottom people despised by people without interpersonal skills and good grades. American higher education has strict management and academic 
requirements. Students have to take their homework and exams seriously if they want to graduate. If they fail, they face retaking the exam or re-studying for a year. Tuition is paid by the students themselves, and because of the high cost many students do not want to waste it and they usually take it seriously. As a result of the lax management of Chinese universities, many students arrive late for class and ask someone to call the roll for them. The students entered the exam room with a cheat sheet when they took the exam and sought an end of studies thesis from the Internet as their end of studies thesis. The success of American in basic and higher education has also resulted in exceptional individuals for society.

\section{DIFFERNECES BETWEEN CHINESE AND U.S. EDUCATION SYSTEM}

China' s education attaches importance to limited but deep contents, while education in the United States focuses on widespread contents [11]. Education in China adopts the "excessive assignments tactic", teachers ask students to practice again and again, so they train students to master knowledge in books until they "did". Mathematics education in American schools is a "light-touched" (A relatively relaxed education model). Some people regard that China's education makes students believe in leaders of authority and hindsight speculation, but Education in the United States allows students to have their own views to explore and pursue truth.

\subsection{Differences in Teaching Modes}

China's education lays emphasis on respecting and maintaining the authority of knowledge, study and learning. Students are expected to master all knowledge of human beings at once. In terms of knowledge in textbooks, students are required to completely master and the authority of textbooks should be respected and maintained. Therefore, people have a stereotype that everything in the book is correct [12].

There is no standard answer in Education in the United States. Almost no two students give exactly the same answer to the same topic. Research conclusion are studied base on the obtained knowledge. However, there is no national curriculum or textbook in American primary and secondary schools. The curriculum setting and difficulties of each school are determined by the school and faculties according to actual situations. American universities and high schools implement credit system, course selection system and professional minor system. The curriculum is comprehensive, theoretical and practical. Students can select optional courses in accordance with their individual interests, different courses have different credits, you can get your diploma and academic degree as long as you obtained the required credits. That' $s$ why so many American college students get several degrees at school [13].

\subsection{Difference between Educations in China and the United States Lie in the Different Teaching Objectives of Primary Education}

Basic education in China takes the development of children' s intelligence and high scores as the primary goal; but in the United States, there is only one target for primary education, that is to cultivate creativity. In class, teachers will guide students to create their own works instead of just explaining knowledge.

\subsection{Different Attitudes towards Achievements}

For our Chinese children, transcripts that make parents dissatisfied often bring great pressure to children, which affects all aspects of learning. In the United States, every student' $s$ final transcript is regarded as the personal property. Parents are not allowed to put too much pressure on their children. For adults, academic performance is far more important than capabilities. But, most of Chinese students aim at obtaining high scores.

\subsection{Different Environments for Students Provided by the Two Countries}

American schools encourage research since childhood, cultivate children's research skills, independent capability to deal with problems and the ability to organize research materials in sports research methods. However, under the restriction of examoriented education and the influence of traditional ideas, Chinese schools adopt a two-stage strategy of "laying the foundation first and then learning".

\subsection{Different Courses of the Two Countries}

Foreign language learning is different in these two counties. In China, students only learn English in the basic stage of education (except for major). This is the unified choice made by the education system for all students.

In the United States, students are more likely to choose moral education, including Spanish, French, Latin and so on. There are courses that need no textbooks in the United States, which are generally called "family life" courses.

The class teaching methods of American colleges and universities can not only guide students to correctly understand and master the correct response of teachers to teaching problems, but also give students a space for free imagination to find potential answers that neither teachers nor our students know. 
In China, except for a few talents who are free from to be judged by scores of college entrance exams, the rest of the students regard the college entrance examination scores as the most important and the only admission standard. While in the United States, students have to take various exams at least once a year. They may have more opportunities to register for the exams than in China.

\subsection{Different Burdens of Learning: Americans Take an Extra Day Off Almost Every Week}

In China, weekend may be occupied without any reason, even if the happy vacation will also be occupied by heavy homework.

\subsection{Different Family Educations}

Education in the United States is very strict. American parents will set many rules, but as their children grow up, these rules become more flexible. On the contrary, Chinese parents spoil their children from childhood, restrict everything when they grow up, and even interfere with college majors and love.

Education in the United States pays attention to cultivate children' $s$ sense of responsibility. Such an education difference makes American children more independent than Chinese children.

\subsection{Different Value Orientation and Moral Education}

Traditional Chinese morality is based on Confucian ethics. Such as "benevolence, righteousness, courtesy, wisdom and trust", "fraternity" advocated by Confucius and "the world is for the common good" advocated by Sun Yat-sen, as well as modern "serving the people wholeheartedly", these moral standards go through China's entire education system. Traditional Chinese

The "individualism" practiced in the United States is also called "putting individual first", which pursues personal ideals and rights. However, American college students should also firmly foster their own capitalist social values, which have been filled with the core ideas of the bourgeoisie, because "an American student must have a minimum experience and understanding of American culture and spiritual traditions, otherwise he will not be a well-educated American" [14].

\section{GENDER}

Gender plays an important role in comparing the differences between Chinese and American system.

\subsection{Gender Stereotype}

People often put labels on men and women due to the gender stereotype. For example, girls are more careful and considerate, so they tend to be good at arts and literature. Boys are adventurous and good at math and science. When this idea becomes ingrained, people will feel natural to think this way. This leads to selfdenial of science fields by women and liberal arts fields by men [15]. What's more, it gradually affects children's career paths later. More women tend to choose teachers, nurses or engage in some service industries. While men will go into some well-paid job, such as science, technology, and engineering. Statistics shows that, In China, the starting monthly salary of male employees was 5,034 yuan, while that of female employees was 4,592 yuan in 2017 [16]. From this, the gender gap in salary still exists.

This kind of gender stereotype also has a great impact on students' learning ability and level. In the past of China, there was a long period that women had been at a disadvantage on the opportunities to obtain knowledge because society discouraged women from going to school. In the early 1970s, through the expansion of higher education, China reduced inequality in educational opportunities significantly [17]. As pointed out by Xie in his paper, nowadays, although we have basically achieved gender equality in education, there are still some shortcomings in terms of teaching content [18]. For instance, parents, schools and society intentionally influence the children by saying the words that boys should be like boys and girls should be like girls. Boys shouldn't wear makeup and girls should behave gracefully. In addition, boys are encouraged to participate in basketball, football and other confrontational sports and girls are expected to take part in gymnastics, skipping, yoga and other sports that conducive to enhance flexibility.

\subsection{Gender Discrimination}

If schools emphasize sex differences in education excessively, then school bullying will occur. Those boys who don't look like boys and girls who do not look like girls will be discriminated by other students. These kids usually have less peer support and do worse academically. Some of them even drop out of school because of anxiety, which is extremely bad for children's physical and mental development.

\subsection{Solution}

To solve these problems. The first step is to educate parents about the importance of receiving education. A good quality of education provides more career opportunities for women, promotes economic growth, and reduces poverty. Moreover, well-qualified women should be provided equal opportunities to gain access to better jobs. Finally, society, schools and families should respect every child. They have control over their lives 
and their future has infinite possibilities. They shouldn't be limited by gender.

\section{CONCLUSION}

Overall, American basic education pays more attention to cultivating students' comprehensive quality. Unlike China, which focuses on students' grades and ignores the rest. Therefore, in the US, even some students with poor academic performance may be appreciated by others for their excellent communication skills. But in China, students with poor grades may become introverted because they are looked upon by teachers and classmates with coloured glasses. In the society, they may become the bottom people despised by people without interpersonal skills and good grades. American higher education has strict management and academic requirements. Students have to take their homework and exams seriously if they want to graduate. If they fail, they face retaking the exam or re-studying for a year. Tuition is paid by the students themselves, and because of the high cost many students don't want to waste it and they usually take it seriously. As a result of the lax management of Chinese universities, many students arrive late for class and ask someone to call the roll for them. The students entered the examination room with a cheat sheet and they took the exam and looked for a graduation thesis from the Internet as their graduation thesis. America's success in basic and higher education has also produced outstanding people for society.

\section{REFERENCES}

[1] Bai, T. Y. (2021). Research on Bullying Governance in Public Schools in California, USA (Master's Thesis, Hebei University). https://sso.gzlib.org.cn/interlibSSO/goto/75/+jmr9b mjh9mds/KCMS/detail/detail.aspx ?dbname $=\mathrm{CMF}$ DTEMP\&filename $=1021701924 . \mathrm{nh}$

[2] Yu, Y. \& S.X. (2019). Research on school bullying behaviours characteristics and social preventive countermeasures-Based on analysis of 50 typical cases of school bullying. Juvenile delinquency (05), 5-15. DOI: CNKI: SUN: FZWT.0.2019-05-003.

[3] Tong, L. (2021). Ten major changes in the revision of the Law on the Protection of Minors. Research on the Prevention of Juvenile Delinquency (01), 411. DOI: CNKI: SUN: YFQS.0.2021-01-002.

[4] Ren, K. (2019). Effective countermeasures for the governance of school bullying in the United States. Shanghai Law Society. (eds.) "Shanghai Law Studies" Collection (Volume 10, Total Volume 10, 2019)-Social Governance of Shanghai Law Society Research Conference Proceedings, pp.31-38.
[5] Yang, D. (2021). Junior high school girl fined 150 squats for life-long disability. Retrieved 12 September 2021, from https://news.ifeng.com/c/89rICYajUUY.

[6] Liang, Q. (2020). A primary school student in Cangxi died after being physically punished by his teacher. Retrieved 12 September 2021, from https://sichuan.scol.com.cn/ttxw/202009/57898823 .htmlA primary school student in Cangxi died after being physically punished by his teacher.

[7] Wu, L. (2011). The right to corporal punishment of American teachers and its legal supervision. Teaching and Education (28), 29-31. DOI: CNKI: SUN: JYYR.0.2011-28-018.

[8] He, L.(2010). On the Similarities and Differences between psychological Reading Guessing Game theory and information processing reading Theory. Reading and Writing (Education Journal)(04),26+35. DOI: 10.16071/j.cnki.cn511650/ G4.2010.04.021. Li, Y.G. Comparison and reflection on the differences between Chinese and American educational concepts $[\mathrm{J}]$. Journal of higher correspondence, 2001,14 (5):5.

[9] Lin, C.D.\& Hu, W.P.(2012). The Growth law and training mode of creative talents. Journal of Beijing Normal University (Social Sciences)(01),36-42. DOI: CNKI: SUN: BJSF.0.2012-01-009.

[10] Shi, Y.M.(2021). The Cultivation of Students' Thinking Ability in English Reading Teaching. Primary School Teaching Reference (27),57-58. DOI: CNKI: SUN: XIjk.0.2021-27-035.Huang L.J. Dai J. Comparison and Enlightenment of Moral Education Goals in Chinese and American schools [J]. China After-school Education, 2008, (8):15.

[11] An, L. Y. (2001, November 08). APA format for Academic papers (6th edition). Retrieved November 20, 2021, from https://www.scribbr.com/apa-style/6thedition/archived-format/ Tian H.W. Comparative Analysis of current Research Methods of Higher Education in China and the United States [J]. China Higher Education Research, 2008, (4) : 28.

[12] Wei, T. H. (2008, November 08). APA format for Academic papers (6th edition). Retrieved November 20, 2021, from https://www.scribbr.com/apa-style/6thedition/archived-format/Wang, Z \& Guan, J. (2021).Positive stereotypes can have negative effects [J]. Advances in psychological Science(09), 1657-

1668.https://doi.org/10.3724/SP.J.1042.2021.01657 
[13] Feng, Z. X. (2008, November 08). APA format for Academic papers (6th edition). Retrieved November 20, 2021, from https://www.scribbr.com/apa-style/6thedition/archived-format/

[14] Jian, H. L. (2008, November 08). APA format for Academic papers (6th edition). Retrieved November 20, 2021, from https://www.scribbr.com/apa-style/6thedition/archived-format/

[15]Xie, G.H. \& Liu, X.Y.(2021).Gender of Mathematics - - The influence of gender concept on mathematics level of junior middle school students [J]. Sociological research(04),201224+230. DOI: CNKI: SUN: SHXJ.0.2021-04-010.

[16]Wang, Z \& Guan, J. (2021).Positive stereotypes can have negative effects [J]. Advances in psychological Science(09),16571668.https://doi.org/10.3724/SP.J.1042.2021.01657

[17]Li, Y.T. \& Zhang, Y,R.(2019).Study on gender Difference of College Students' Starting salary-_ The social cognitive bias perspective [J]. Journal of North China University of Science and Technology(05),94-97+106. DOI: CNKI: SUN: HLXB.0.2019-05-017.

[18]Hannum, E., Ishida, H., Park, H., \& Tam, T. (2019). Education in east asian societies: Postwar expansion and the evolution of inequality. Annual Review of Sociology, 45(1), 625-647. DOI:10.1146/annurev-soc-073018-022507

[19] Xie, G.H. \& Liu, X.Y.(2021).Gender of Mathematics - - The influence of gender concept on mathematics level of junior middle school students [J]. Sociological research(04),201224+230. DOI: CNKI: SUN: SHXJ.0.2021-04-010. 